Canadian Journal of Family and Youth, 8(1), 2016, pp 47-71

ISSN 1718-9748 (C) University of Alberta

http://ejournals.library.ualberta.ca/index/php/cjfy

\title{
The Effects of Neighbourhood, Community, and Social Networks on Marginalized Youths' Well-being: An Arts-based Approach
}

\author{
Kevin de Leon, Lynda M. Ashbourne, \& Jane Robson
}

\begin{abstract}
Action research and arts-based activities were used to investigate the experiences of youths, ages 16-20 years, in the Guelph community who identified as being socially marginalized through poverty and/or unstable housing. The focus of the group was on identifying the influences of structural violence in their lives. As part of their discussions, they identified the ways in which their personal safety and well-being, their sense of feeling comfortable and included in the broader community, and their presence and role within this community were influenced by the ways others in their neighbourhoods and social networks treated them. In particular, they described the assumptions and treatment by others that were based on classism and ageism as excluding them and threatening their feelings of safety and well-being when living on the street and/or receiving social assistance. The youth group expressed these ideas through discussion, photovoice, and drawing their version of a 'community map.' This paper includes examples of these participant-produced arts projects to demonstrate their observations and ideas.
\end{abstract}

Kevin de Leon is a Master's student in Family Relations \& Human Development, Department of Family Relations \& Applied Nutrition, University of Guelph, kdeleon@uoguelph.ca. His research interests are in the area of parentadolescent relationship and its influence on the development and maintenance of self-compassion and self-criticism. Lynda M. Ashbourne, Assoc. Prof., Dept. of Family Relations \& Applied Nutrition, University of Guelph, Guelph, Ontario, Canada N1G 2W1, lashbour@uoguelph.ca, is a co-investigator on the "Voices Against Violence" team research project (CIHR). Her research interests include using qualitative methods to examine relational and broader systemic influences on parents and adolescents. Recent publications include: 1) Ashbourne, L.M., \& Baobaid, M. (2014). Parent-adolescent storytelling in Canadian-Arabic immigrant families (Parts 1 \& 2): A grounded theory. The Qualitative Report, 19(59), 1-21 \& 19(60), 1-18; and 2) Ashbourne, L.M., Daly, K.J., \& Brown, J.L. (2011). Responsiveness in father-child relationship: The experience of fathers. Fathering, 9(1), 69-86. DOI: 10.3149/fth.0901.69. Jane Robson is a PhD student in Family Relations \& Human Development, Department of Family Relations \& Applied Nutrition, University of Guelph, jrobson@uoguelph.ca. Her research interests are in the area of parent-child relationships and parenting programs directed at noncompliance.

\section{Acknowledgements:}

This project was supported with funding from the Canadian Institutes of Health Research. This paper is part of the CIHR Team grant "Promoting Health through Collaborative Engagement with Youth in Canada: Overcoming, Resisting, and Preventing Structural Violence" conducted under the leadership of Dr. Helene Berman, Western University. A full list of team members can be found at www.voicesagainstviolence.ca. This paper rests heavily on the contributions of the six youth who participated in the group discussions and arts-based productions. 
de Leon, Ashbourne, and Robson

\section{Introduction}

In this paper we report on how a group of youth who are experiencing marginalization in their community due to poverty or precarious housing describe and express the influences of structural violence on their sense of belonging and social inclusion. This small group project was part of a larger research program ${ }^{1}$ exploring the everyday experiences of various and diverse groups of young people in Canada in relation to the subtle and explicit influences of structural violence, how it affects their health and well-being, and what strategies they use to resist it. The group of young people we report on here, ages 16-20 years, engaged in participatory action research (PAR) and produced arts-based expressions of their daily lived experiences in a midsized urban centre in Ontario, Canada. Themes related to their sense of safety, inclusion, and presence in their local community, were evident in their discussions and arts-based explorations of structural violence and its impact on their well-being. We present these themes, with support from the participants' discussions and artistic rendering of their experiences.

\section{Literature Review}

Structural violence is a term that refers to the ways in which institutions and systems within society both create and maintain inequality between social groups. According to Galtung $(1969 ; 1990)$ these structures, by withholding resources from individuals, marginalize and exclude certain members of society and "normalize" these inequalities, solidifying their place within society and maintaining patterns of exclusion due to social identity markers, such as gender, race, or class.

\footnotetext{
${ }^{1}$ Promoting Health through Collaborative Engagement with Youth in Canada: Overcoming, Resisting and Preventing Structural Violence (PI Dr. Helene Berman), renamed "Voices Against Violence" by our National Youth Advisory Board, is funded by Canadian Institutes of Health Research (2011-2016). See website at www.voicesagainstviolence.ca.
} 
In 2011, approximately 13\% of Canadian children under the age of 18 were low-income (Statistics Canada, 2013). Poverty is directly linked to a lack of affordable housing (Gaetz, Gulliver, \& Richter, 2014). Both of these life circumstances negatively impact children's and youths' physical and emotional health and well-being, as well as school attendance and performance (Hick, 2007; Webster \& Perkins, 2007). According to Hwang, Guirguis-Younger, and McNeil (2014), in Canada, the fastest growing group of individuals who are homeless are youths between the ages of 16 and 24 years old.

Though negative views of homeless youths still persist, more recent perspectives acknowledge structural and contextual factors contributing to their circumstances (Gaetz, O'Grady, \& Buccieri, 2010). Some of these factors include a lack of affordable housing (as noted earlier), family conflict and dysfunction, physical and/or sexual abuse, and poverty (Gaetz et al., 2014; Martinez, 2006; Smith, 2008; Stein, Milburn, Zane, \& Rotheram-Borus, 2009; Whitbeck, Hoyt, Yoder, Cauce, \& Paradise, 2001; Zielinski, 2009). These factors are not necessarily mutually exclusive and contribute to the complexity of challenges homeless youths face on a daily basis, potentially collating to broader structural barriers and consistent experiences of social exclusion, victimization, and safety within the community.

According to Silver (2008), social exclusion is a "dynamic process of progressive multidimensional rupturing of the 'social bond' at the individual and collective levels" (p. 1). This social bond that Silver (2008) describes is composed of social relationships, structures and institutions, and an overall sense of "belonging." This exclusion disallows individuals from being a part of their community by placing various restrictions and limitations on their being and living. Social exclusion is a "structural process of social isolation, of stripping away multiple dimensions of social involvement" (Silver, 2008, p. 2). 
de Leon, Ashbourne, and Robson

Gaetz (2004) examined the role of social exclusion in the lives of youths who are homeless. These youths experience various restrictions because of this marginalization, including difficulties in seeking adequate, safe, and affordable housing (Gaetz, 2004). Placing limitations on the spaces these individuals can stay may expose them to harmful circumstances, affecting their safety and increasing the risk of becoming victims of crime (Gaetz, 2004). For example, street youths have reported being "kicked out" of public locations by the police, such as parks and malls, which can increase their exposure to potential criminal offenders (Gaetz, 2002).

Gaetz (2004) also discussed the role of social relationships and how these can influence street youths' feelings of safety. Many of these young people have weak social capital and may not be able to rely on family or community members to enhance their security, such as through staying with and protecting them, which may be particularly crucial for adolescents (Gaetz, 2004). Indeed, Brevard, Maxwell, Hood, and Belgrave (2013) found that having intergenerational connections, which is when youths feel connected to and support from adults in their neighbourhood (Sampson, Morenoff, \& Earls, 1999), can increase youths' feelings of safety and security, even if their community is characterized by high crime rates and poor economic conditions. This sense of safety is linked to adults beyond parents, including community members; youths must feel that the adults around them are concerned with their well-being (Brevard et al., 2013). Additionally, social exclusion is typically additive in nature and homeless youth, for example, may be limited in their access to employment opportunities due to their age, inexperience, and poverty (Gaetz, 2004). Restricted access to adequate housing and employment feed into each other, resulting in a cycle in which many homeless youths find themselves.

Participatory action research (PAR) focuses on collaborating with community members who are directly involved or affected by a problem (Rodriguez \& Brown, 2009), involving them 
as co-researchers in the research process (Conrad \& Kendal, 2009). PAR emphasizes the expertise the co-researchers possess due to their consistent contact with the contexts and issues that are being examined (Rodriguez \& Brown, 2009) and focuses on developing knowledge and action for those directly affected.

\section{Current Study}

The larger project, of which this group is a part, is directed by a national team of researchers and a youth advisory council, and comprised of a number of local research projects taking various perspectives on the effects of structural violence on diverse groups of youths. This CIHR-funded project examines structural violence in the everyday lives of youths across Canada and its influences on their health and well-being. The purpose of the project was to examine the ways in which systems/institutions, policies, and the media can contribute to elements of structural violence that influence youth directly regarding their sense of identity, self, or social inclusion.

The purpose of the current study we are reporting on was to investigate how structural violence influences the everyday lives of youths who have self-identified as being socially marginalized due to economic disadvantage and/or precarious housing. By working and collaborating with the youth participants, we were able to facilitate their exploration and expression of structural violence in their lives.

\section{Methods}

Upon obtaining ethics approval from the University of Guelph, thirteen youths were initially recruited through advertising at various community centres and local agencies in a 
de Leon, Ashbourne, and Robson

midsized city in South-Central Ontario, Canada (population approximately 120,000). Not all of these youths were able to consistently attend group meetings for the duration of the study, and the final group was comprised of six members. The participants' ages ranged from 16-20 years, with three participants who identified as male and three as female; ethnicity and sexual orientation were not explicitly noted during recruitment by the youth participants. The youth self-identified as having had personal experiences of marginalization, primarily associated with homelessness (i.e., inconsistent and unstable living arrangements), but also including experiences with providing aid to others who were homeless (e.g., giving a friend a temporary place to stay). At the time of the study, the participants' living situations were varied: some youths were renting an apartment, others living with their parents, and some staying in youth shelters. Some of these participants were in school: two youths were finishing their studies in secondary school and two were in an alternative education program. The remaining two participants had dropped out of school at the time of the group.

In this study, participatory action research (PAR) methods, arts-based activities, and discussions were used to facilitate and engage the youths in reflection and expression of their experiences, views, and knowledge of structural violence and how it relates to homelessness. The group lasted for ten weeks; youths attended three-hour weekly sessions at a local community centre. Two group facilitators (first and third authors), male and female graduate students, ages 25-28, at the University of Guelph, facilitated group discussions in consultation with the second author, co-investigator on the larger research project team. Activities were guided by the youth participants' interests in relation to an overall focus on how structural violence might be understood in the context of their lives. 
During the first session, the facilitators encouraged the creation of a safe context for meetings, including confidentiality and respectful interactions, and introduced the project to the youth participants. The facilitators worked in tandem with the youth to develop a working definition of structural violence, including examples of how it might look in these youths' daily lives. This definition and the associated examples were continually re-examined and modified throughout the study as the group participants developed and refined their understandings.

Each weekly meeting followed a format of checking in with the youth participants about their current experiences and linking these to earlier discussions. More in-depth discussions followed, with topics determined by participants. Following the group conversations, the youth engaged in arts-based activities that provided a venue for expressing their reflections, observations, and experiences linked to these discussions. During the activities and discussions, the group facilitators would work with the youths to make notes of themes that would arise. This process ensured that the participants' messages were not lost and that the notes reflected what the youth intended at the time.

Over the course of ten meetings, the participants engaged in a range of arts-based activities including creating comic strips, collages, community maps, paintings, self-portraits, and masks; and completing a final photovoice project over several weeks. In order to present the youth researchers' examination and expression of their experiences with regard to neighbourhoods and social networks, as well as feelings of safety and inclusion, we focus primarily on the community maps and photovoice project. The community maps were drawn by the participants to present their sense of the spatial organization of their surroundings and influences of structural violence. In particular, these maps identified spaces of safety and risk, as well as access to services and public spaces. Photovoice (Wang, 1999) allows participants to 
de Leon, Ashbourne, and Robson

“identify, represent and enhance their community through a specific photographic technique" (Wang, Cash, \& Powers, 2000, p. 82), and can be used to "promote critical dialogue and knowledge about personal and community issues through group discussions of photographs" (Wang, 1999, p.185). For this photovoice project, the youth participants were provided with cameras and basic photography training, and discussed together what type of photos might best reflect the themes of their discussions and work over the course of the project. The youth participants used their understanding of structural violence as the "lens" through which they viewed the community as they took the photographs, focusing on imagery that captured what they felt to be representative of their, as well as the other group members', experiences of homelessness and classism. Once all of the photos had been taken, the group members finalized which photographs would be included in the photovoice presentation. The youth participants organized and structured the photo display using Microsoft PowerPoint and included music, personal messages, and quotes to complete the presentation which was uploaded to the national research project website for public dissemination. The following results will present the participants' experiences using direct quotes, paraphrased stories, and photos. These results will be identified with pseudonyms, with one exception due to Devin's explicit request that his actual name be used.

\section{Results}

In this section, we present the themes related to neighbourhood and communities, safety and social inclusion that were identified by the youth researchers and expressed in their discussions, community maps, and photovoice presentation. Although the youths did not 
specifically refer to well-being, they did link aspects of well-being, such as physical and mental health, to safety.

\section{Safety within the Community}

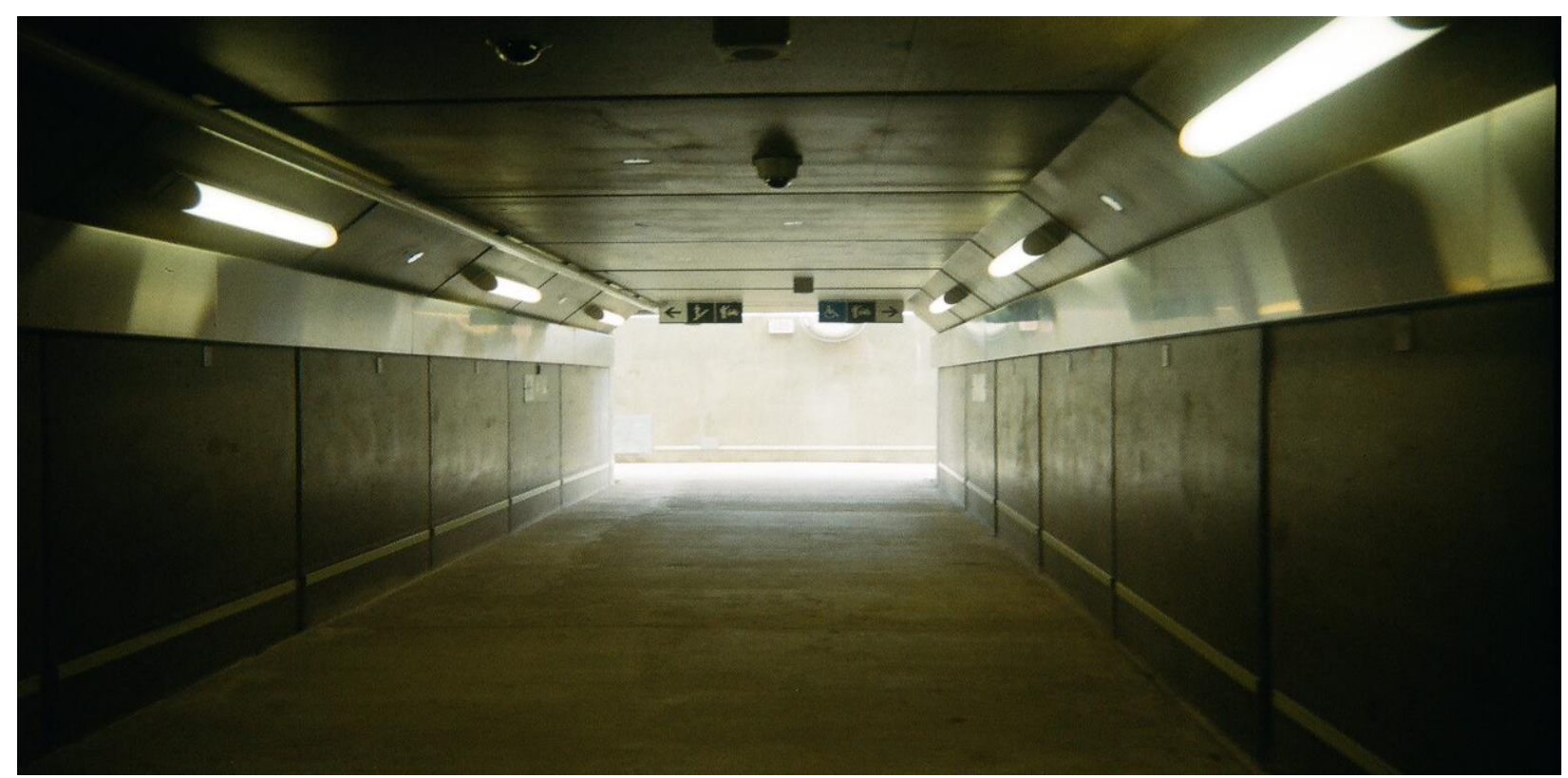

Photo 1: "A safe place to sleep"

The youth participants defined safety in relation to the spaces and organizations within their community (see Photo 1). More specifically, they described feeling safe in places where they would not be disturbed by others of the community (e.g., police officers), whether they used these areas to sleep, meet with friends, or simply rest and "hang out." They also discussed feeling safe in places where they would not be at risk of being a victim of crime, particularly of theft.

The group members' definition of safety was also intertwined with their definition of what a home is. One youth researcher, Grace, stated that a home is a "place where you feel the most safe with yourself... because it's confined, no one can come in there, it's filled with your own stuff, and you can be yourself." Devin elaborated, explaining that a home is "somewhere that you can safely fall asleep and know that you are going to wake up safely." 
During this discussion, the group members spoke about how the home can also be a source of feeling unsafe. To illustrate this, Devin shared his story of how he came to be homeless. He explained that he and his step-mother were not getting along and eventually, in an argument, she threw something at him and told him to get out. Devin stated that this was his breaking point and that he left his home immediately after. Devin described being homeless on and off since that argument occurred.

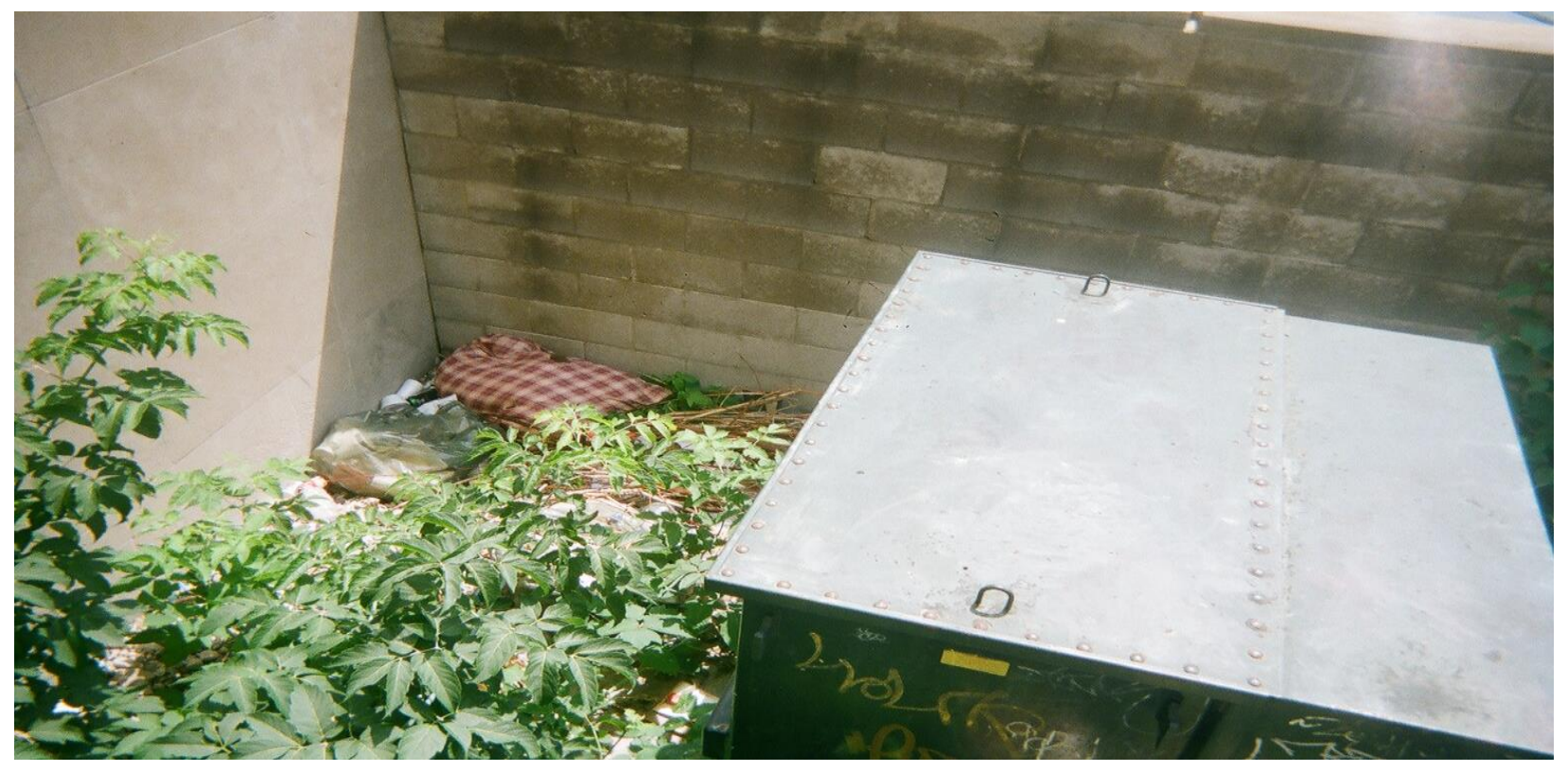

Photo 2: "A secluded location to sleep"

Safety is a key component that these youth factor in when choosing places to sleep outside of the home as well, they noted. In one of the photographs taken (see Photo 2), Lauren, who captured the image, said that, "not a lot of people know that this place is even here, which is a bonus to tenants who don't want to be disturbed or robbed." The potential to be robbed is something that Lauren recognized as a possible outcome by sleeping there. The fact that this location is relatively unknown to others is what creates a sense of safety, she said. However, it is not always possible to stay in a safe space, some members explained. Lauren wrote about this notion and linked it to another photo (see Photo 1), “...it isn’t a big surprise to see people 
sleeping here. This is in a very drug oriented part of downtown and nothing good ever seems to happen here."

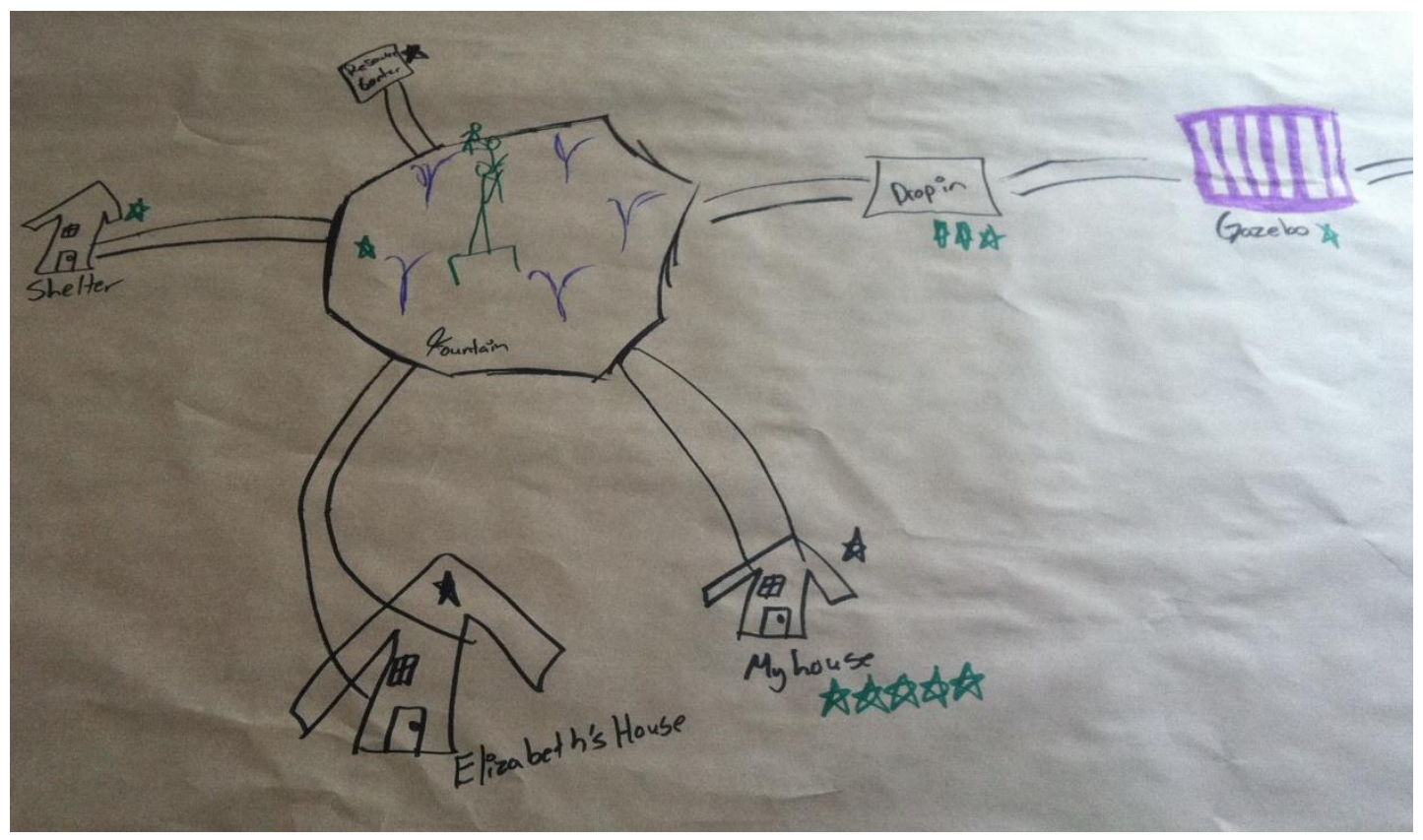

Photo 3: "A community map"

Additionally, many of the group members expressed that this seclusion was important to ensure that they would not be disturbed by the police. For example, many of the group members identified a gazebo in a park, as seen in the community map below (see Photo 3). Devin stated that police officers would often force him to leave certain areas, such as park benches, bus stops, and a formerly safe spot behind a church—-this location was considered to be safe until police officers learned of its presence-limiting where he might find shelter or a place to spend time. Devin explained how crucial it was to find places, like the gazebo, that police officers did not frequent so that he had somewhere safe to sleep, such as under a bridge on the outskirts of downtown (see Photo 1). 
The youth group identified other safe and unsafe areas within their community through the photovoice presentation and mapping activity. Below is a photograph of a safe place the participants chose and presented in their photovoice (see Photo 4):

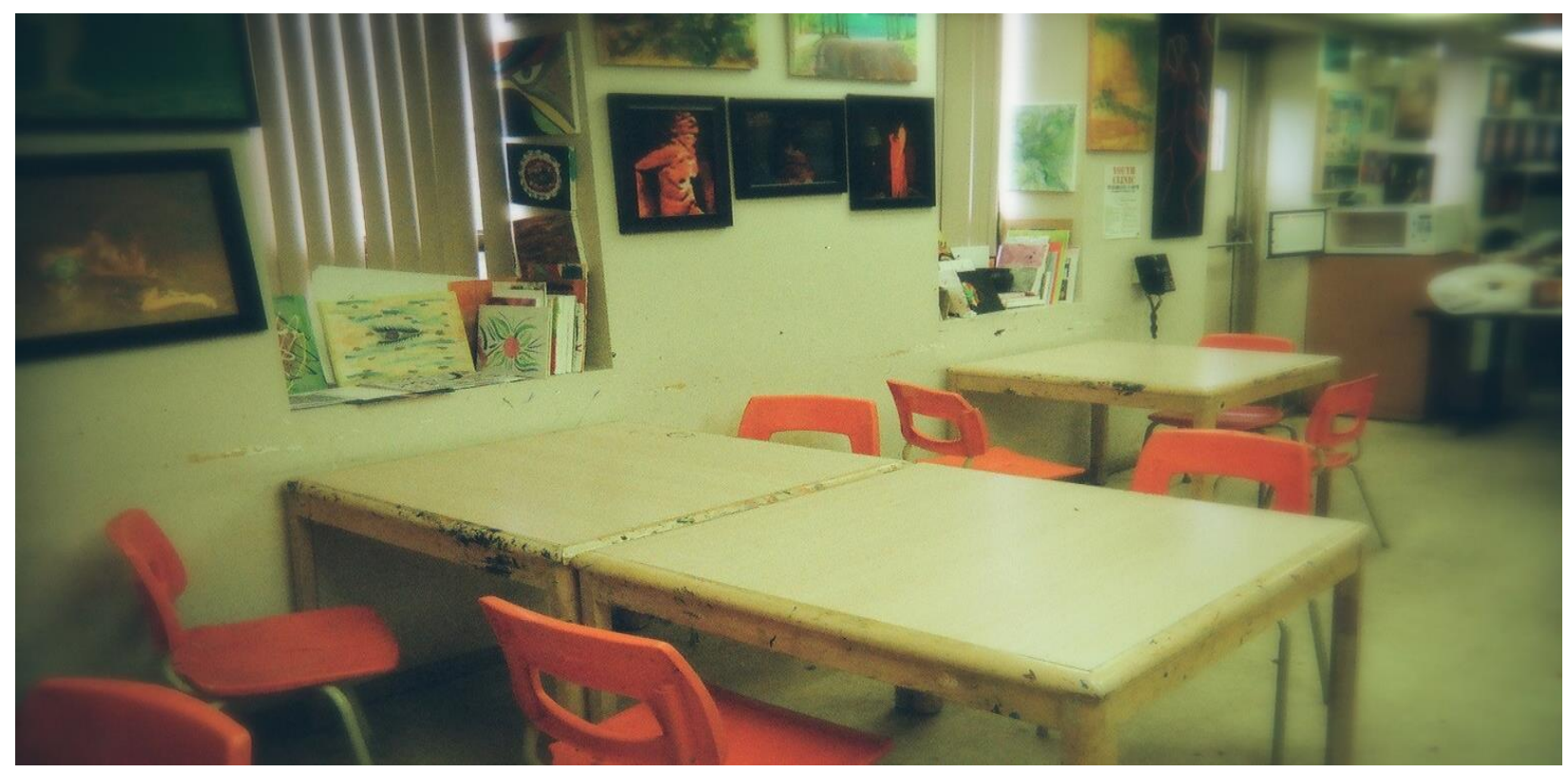

Photo 4: "Photograph of a community centre downtown"

"This is a community center downtown...where all sorts of people gather (i.e. drug users, homeless, punks, criminals, etc,)...dinner is provided each day and a variety of resources are also provided."(Heather) Heather identified this community centre as a place where homeless individuals can receive shelter and food, as well as a place where they can meet and "hang out" with other young people. Devin said, "I met other people at shelters and some of them would teach me where to go, where to eat, where to sleep, and what to do.” The relationships that can originate through these spaces create a sense of safety, some participants stated. They expressed that seeing their peers at these local places and creating a "youth community" can make some spaces in their community feel like "home." During the community mapping, many of the youths included rating systems to evaluate how safe or unsafe some places were, in addition to demonstrating how helpful or unhelpful some locations were. 
Below is Heather's community map.

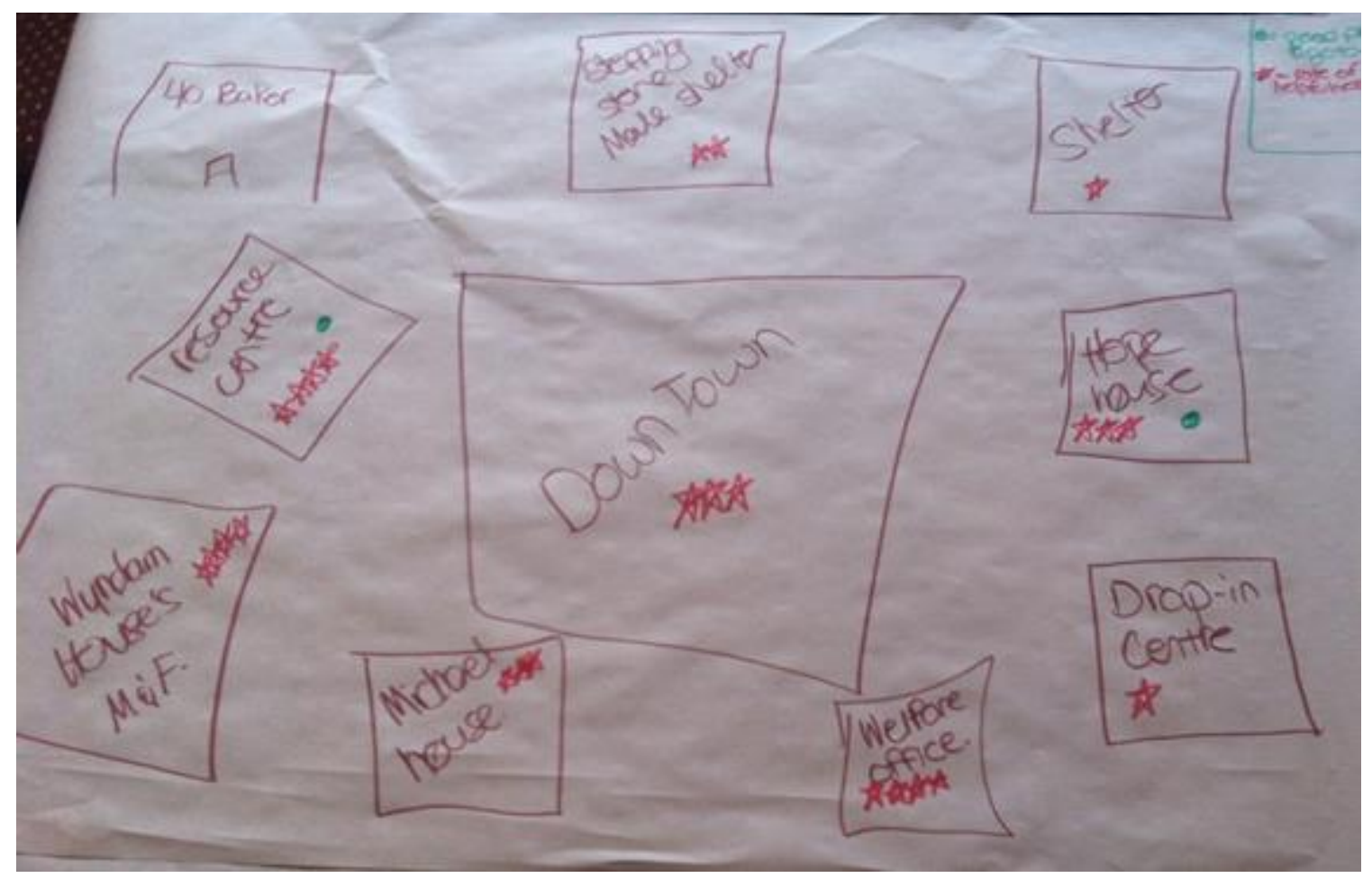

Photo 5: "Community Map"

Many participants identified the large fountain in the centre of downtown as the central hub of their communities, stating that this was their "chill zone." Though some of these youths stated that they still spend time and congregate with peers at the fountain downtown, many indicated that this area no longer felt safe to them. Heather explained that the reason they felt downtown used to be safe was because "there were always people around" and because of the constant presence of police officers. Since the bus stops and station had been recently moved to a different part of downtown, the number of people around the fountain area had dwindled, and these participants reported feeling less safe in the downtown area more generally because of this.

When asked what makes a safe (or unsafe) place in their community, the participants emphasized the role of the individuals that make up their community. Some youths identified their families as playing a big role in their feelings of safety. One youth, Kris, spoke about a time 
de Leon, Ashbourne, and Robson

when his family took in a friend of his when he was kicked out of his home. Although Kris explained that "it was hard" because "[letting him stay] costs money and we have to feed him and take care of him," he felt that this act was important in helping his friend feel safe by providing him with a place to stay when he had nowhere else to go. Conversely, Devin's story of how he came to be homeless, discussed earlier, was used during this conversation to illustrate how the family can create an unsafe space.

The youth researchers also described their experiences with service providers and how they have influenced their feelings of safety. Heather shared her experiences with individuals working in a drop-in centre she frequents. She explained that some of the workers have been there for a long time and do not like their jobs. She stated that some of these individuals treat the people who need their assistance poorly, which has made her feel unwelcome and not cared for. However, the youths also explained that there are some service providers who have worked in the community for a long time because they truly want to help people. Heather said, "the only people that should work [as service providers] are the ones that want to help; that can help you make change." Both Grace and Heather used their social workers as examples of the sorts of people who should work in their communities because of the positive experiences they have had.

The participants also identified the shelter system as a structure within their community that affected their well-being and safety. Many of the youths shared their frustrations with the emergency shelter because of the restriction it places on its patrons with regard to their duration of stay. Since homeless individuals are only allowed to stay at the emergency shelter for a certain amount of time, many of the participants felt this influenced the ways in which both the workers and guests treated the space and each other. Devin, for example, explained that his and others' possessions would often be damaged or stolen because of the transient nature of the shelter's 
members. He elaborated by sharing various stories of fights that were sparked by issues of theft between other members at the shelter. Heather described a similar experience, but also felt that the constant flux of people coming in and out affected the condition of the shelter's equipment, such as the beds. Since the patrons knew they would be leaving shortly, both Heather and Devin stated that many of the other members would not take care of the equipment they were given without being reprimanded due to a lack of supervision by the staff, so when they came in, their spaces would not be of good quality, which affected their stay.

The youth group members also discussed how the short-term stay of so many people affected how they were treated by the workers at the emergency shelter. Devin spoke about his experience with a certain worker, stating that "she doesn't care" regarding the quality of his stay. Both Devin and Heather mentioned that they felt unwelcome at the shelter since the workers knew that they would not be long-time guests. Devin elaborated, stating that a "shelter should be a roof over your head from the cold and rain, but instead, it's just a place that someone lets you sleep."

\section{Exclusion from the Community}

These youths also discussed and defined what a community is and how they viewed their own communities. Although some participants felt that the youth population itself is a community, “there isn’t a group of adults who are supporting us as a community” (Heather).

This led to an overall feeling of a "lack of community." Kris elaborated, "kids aren't taught how to be a community or how to act in a community. That's why we aren't a community. Nobody teaches us." Heather agreed, explaining that "not everyone was raised to take care of each other." Having support and help from members of the community was important to the youth group: “people should care, even if you don't have a personal experience of it [violence]. You should 
de Leon, Ashbourne, and Robson

still help and get other people [to] pitch in to help.” (Grace) Heather responded, “...one person helping each other, and then after time, everyone will help each other and we can make changes." However, this notion of creating change was only deemed as possible "when there is leadership...[then] there can be action" (James).

This lack of support from adult community members was identified by the youth participants as leading them to feel that they did not belong, which contributed to feeling overlooked and excluded. For example, Devin shared a story of being excluded by members from his neighbourhood. He explained that there was a barbecue at a nearby house, which was meant to be an open party for those who resided in that neighbourhood so that they could mingle and socialize. Upon arrival, however, he felt overlooked and excluded because he was not approached by any of the attendees; they did not attempt to speak with him, nor did he feel they acknowledged his presence. He said he felt awkward because of this lack of interaction, and explained that this is why he felt he was not a part of the neighbourhood community. Grace also shared a story of how she was treated by others in her community: "One time, a lady and her kids crossed the street to get away from me or my friends. Like, we aren't going to jump you. I love kids. Sorry I don’t look like you.” (Grace)

Social exclusion was also illustrated when the group members identified and discussed a separation between "Downtownies" and people who live in the south end of the city. Differences such as income, clothing styles, and music preferences were noted as domains where these groups differed. An emphasis was placed on a differences in class, with Kris stating that "everyone who lives there is rich with nice houses." Most of the participants self-identified as being a Downtownie and because of this, felt they were viewed as "dirty" by others. For example, Heather talked about a policy that the municipal government had been exploring: 
converting the fountain into a roundabout. Heather believed that this was a form of oppression by the government to "kill our chill zone because the city doesn't want 'dirty' people downtown." These feelings of exclusion affected how they viewed their own presence and role within the community, which will be discussed next.

\section{Presence and Role within the Community}

In addition to feeling overlooked and excluded from their community, the participants described a general feeling of not having any presence within the broader community, mainly because they felt that they are not a community. Many felt that, without having any presence (e.g., not taken seriously by community members, being overlooked and excluded), their role in creating an impact or "real change" in the community was diminished. The youth researchers felt that only parents and other adults have the power to create change structures or systems that contribute to structural violence. The participants further explored the role of adults by defining what an adult is.

Kris focused on the biological aspects of becoming an adult, "straight up how old you turn," while others focused on experience: "so, like, if you are done schooling, have a job, live in your own apartment, then you are an adult" (Lauren). Devin concurred and linked experience to structural violence:

...like, someone who has experienced structural violence may be quicker to become an adult because they don't have a choice and they have to make out every thought... [make] decisions earlier in their life. People who have experienced structural violence have experienced the good and innocent parts of the world, but also the bad, and we need... to learn how to stay away" (Devin).

Participants described the power that parents, as adults, have in determining whether or not they, as "kids", remain at home and supported financially. "Parents have the power to make 
de Leon, Ashbourne, and Robson

change and be in control. They can kick you out or make you go to school or pick what you eat" (Lauren).

The youth researchers explained that one aspect of structural violence is the view, held by other community members and organizations such as Ontario Works and other governmental agencies, that "kids" do not warrant serious attention. Extending this exclusion of young people is the further belief that only adults and those with power can be agents of change in a community. For example, Grace stated that the government is not helpful because "they are jerks and sometimes they just do whatever they want. They never listen to you and they don't take me seriously because I am just a kid.” Heather built on this, “only the government can change structural violence, if they get together. They have the power and leadership skills.” Grace responded, "people in power also have the ability to control and be selective about bringing attention to only certain incidences of structural violence...it's not about us. That's not as important." Being unable to create change because they are "just kids" rather than experienced adults influenced their sense of having a presence within the community, feeling that they could not play a role in having an impact because they are not taken seriously by community members.

I don't believe in that kind of change... [structural violence] happens in Canadain Ontario - it's happening here and why aren't we doing anything about it? Because we aren't a community. (Kris)

Kris recognized and explained that having a community and being a part of it can aid in engendering change, particularly against structural violence, but without having a community and having a presence within it, this ability to create change is rather difficult. Further, Kris expressed how difficult it would be to create a large enough impact in his community by himself, stating that "there is no butterfly effect. Money controls everything and if we don't have the money, then it's not going to matter...making change is hard; it's like the wild." He explained 
that the only way to truly initiate change is by having a widespread impact, "getting the word out to our government. Everyone needs to know." He elaborated, "change is when the entire world knows it." He did not think he had a strong enough presence in his community to create a real change because he does not have the control to do so and because he is only one person. Without control and a "loud enough voice," others in the community have the ability to maintain structural violence, such as homelessness.

When the youths discussed who has control to act as agents in structural violence and homelessness, Kris identified the owners of the house. He stated that home owners (e.g., landlords) "put people down or take advantage of that control in the hopes of making themselves bigger-insult other people; try to make them feel less. People who do that do it to make themselves feel stronger." He explained further:

It's like inflicting that kind of pain on people is what gives people control and power. It goes right to their head and then comes out as structural violence. Because all these people are dependent on them - they need me more than I need them-I can treat them however the fuck I want. (Kris)

Other participants identified power as being important in having a role to enact change. Devin said, "it's all about power. People in power have a chance to make change." Kris used the mayor and prime minister as examples of people in power who can create change, stating "[their] experience gives [them] power.” Lauren agreed, “...because he has been through stuff and seen stuff and has come out the other end." The youths also linked power to community: "...there is power in numbers. In a gang, there is way more noise and so people hear them because they have more of them with the same message" (Kris). By having a strong presence in the community through control and power, individuals can play a significant role in creating change. However, since some of the youth researchers did not feel that they have a strong presence, they cannot fulfill this role. 
de Leon, Ashbourne, and Robson

Not all of the youth participants believed that their presence was weak, however; some youth participants did feel that they could play an important role in having an impact on their community. Some ideas were raised, such as educating other community members on what structural violence is and helping them see different perspectives on those who are marginalized by it. When talking about helping homeless individuals more specifically, Lauren said "everyone is going through their own story and maybe there's some ways we can help." Grace built on Lauren's idea, stating that she wants "people to know that there is help and that we can make changes with the right kinds of support." Heather agreed and stated that she wanted people to know that she cares about them and that she can motivate and help them with their drug usage. She said, "I want to be a light in the darkness."

\section{Discussion}

In this project, PAR was used to support and collaborate with these youth to extend our shared conceptualizations and understanding of structural violence based in their context of homelessness and poverty. The youths involved in the current study identified the ways in which certain changes to the downtown area; organizations such as the police, government agencies, and emergency shelter; and people within the community affected and influenced their feelings of safety, social inclusion, and roles within their community.

The participants in the current study stated that they did not feel that they had a group of adults who supported them, which led to a feeling of a lack of community. Similar to Brevard and colleagues' (2013) research on intergenerational connections between youths and adults within the community, many of the participants believed that they were not cared for nor looked after by members of the community, which negatively affected their experiences in their day-to- 
day lives on the street and receiving social assistance; they felt overlooked, excluded, and unwelcome. Further, their overall sense of belonging was influenced by these feelings.

The youths identified segregation within their community based on class, which affected their senses of identity, such as being viewed as dirty by others because they were Downtownies. Stories of how they were treated by community members, such as Devin's barbecue party, emphasized how some youths felt that there truly was a difference between them and others. These experiences led them to feel that they were not a part of the neighbourhoods in which they lived; that they did not belong to the broader community because they were Downtownies. This falls in line with Silver's (2008) discussion of social exclusion and how it affects youths' sense of belonging.

Moreover, the group members expanded on their relationships with certain adults in the community, such as parents and home owners, by discussing feelings of differences in power and agency. Some youths felt that they did not have the same levels of power and ability to influence change as did some other community members. Structural and organizational exclusion from positions of influence contributed to their beliefs that they could not have a strong presence or an important enough role to enact change. Since they are "just kids," not only do they have limited influence in their own dealings with community members, they cannot help others who have been marginalized or excluded. In fact, some youths explicitly identified the powerful influences that parents can have, specifically with regard to homelessness, in that they can kick their children out of the family home. This tied into feeling unsafe in the community due to the loss of a safe place to call home (Gaetz, 2004).

Barriers that serve to limit their access to safe areas in the community mean that some youth had to withdraw to relatively unknown locations in order to rest without being disturbed or 
de Leon, Ashbourne, and Robson

harassed. Seclusion was viewed as important in feeling safe because it could protect them from being robbed. If homeless youths cannot find secluded, safe areas to sleep, they could very well become victims of various forms of crime, including robbery. This idea relates to Gaetz's (2004) research on the greater vulnerability to victimization homeless youths experience due to being forced out into public spaces. He suggested that, by frequenting areas that are "dangerous," youths are placed in situations that increase the likelihood of encountering transgressors and being victimized. Thus, parents who kick their children out of their homes when they have nowhere else to go, such as seen in Devin's experience, are increasing their children's chances of becoming victims to crimes such as theft or assault.

Despite these negative experiences, the participants did discuss the positive influence their relationships with peers can have on their sense of safety. By having relationships with other young people at the places they frequent, and creating a youth community, these locations were deemed as safe and even felt like "home."

Although this study provided insight into the ways some young people view and experience structural violence in their daily lives, the youth participants were not always able to attend the group sessions, which may have had an influence on the group. The youths explained that they did not have an alarm clock or anyone staying with them that could ensure they were at group on time. Furthermore, over the course of the group, one of the participants was hospitalized and another was admitted to a residential treatment program. We believe that the inability to attend group regularly reflects some of the complexities, unpredictability and inconsistencies evident in the lives of the youth participants. 


\section{Conclusion}

This study explored the ways in which young people conceptualize and view structural violence in their day-to-day experiences. The youths identified issues regarding feeling safe in their community, being excluded by community members and organizations, and having difficulty defining their roles and presence within their community. These youths' experiences demonstrate the role of community members, municipal design, and organizational practices in contributing to feelings of inclusion in one's society. Their stories and photo-expression contributes to our understanding of the links between structural violence and poverty; helping organizations and community workers to develop more comprehensive and informed interventions for other street youths; and encouraging future research to examine successful strategies for enhancing the voice, presence, and agency of young people at a community level. 
de Leon, Ashbourne, and Robson

\section{References}

Brevard, J., Maxwell, M., Hood, K., \& Belgrave, F. (2013). Feeling safe: Intergenerational connections and neighbourhood disorganization among urban and rural African American youth. Journal of Community Psychology, 41(8), 992-1004. doi: 10.1002/jcop.21588

Canadian Observatory on Homelessness (2012). Canadian Definition of Homelessness. Retrieved from http://www.homelesshub.ca/homelessdefinition/

Conrad, D. \& Kendall, W. (2009). Making space for youth: iHuman youth Society \& arts-based participatory research with street-involved youth in Canada. In D. Kapoor \& S. Jordan (Eds.) Education, participatory action research and social change: International perspectives (pp. 251-264). New York: Palgrave Macmillan.

Gaetz, S. (2002). Street justice: Homeless youth and access to justice. Toronto: Justice for Children and Youth.

Gaetz, S. (2004). Safe streets for whom? Homeless youth, social exclusion, and criminal victimization. Canadian Journal of Criminology and Criminal Justice, 46(4), 423-455.

Gaetz, S., Gulliver, T., \& Richter, T. (2014). The state of homelessness in Canada 2014. Toronto: The Homeless Hub Press.

Gaetz, Stephen; O’Grady, Bill; Buccieri, Kristy (2010) Surviving Crime and Violence Street Youth and Victimization in Toronto. Toronto: JFCY \& Homeless Hub. Retrieved from http://homelesshub.ca/sites/default/files/Surviving\%20the\%20Streets.JFCY_.September1 6.2010.pdf

Galtung, J. (1969). Violence, peace, and peace research. Journal of Peace Research, 6(3), $167-$ 191.

Galtung, J. (1990). Cultural violence, Journal of Peace Research, 27(3), 291-305.

Hick, S. (2007). Social welfare in Canada: Understanding income security $\left(2^{\text {nd }}\right.$ ed.) Toronto, ON: Thompson Educational Publishing.

Hwang, S., Guirguis-Younger, M., \& McNeil, R. (2014). Homelessness and health in Canada. Ottawa: University of Ottawa Press.

Martinez, R. J. (2006). Understanding runaway teens. Journal of Child and Adolescent Psychiatric Nursing, 19(2), 77-88. doi:10.1111/j.1744-6171.2006.00049.x

Rodríguez, L. F., \& Brown, T. M. (2009). From voice to agency: Guiding principles for participatory action research with youth. New Directions for Youth Development, 2009 (123), 19-34. doi:10.1002/yd.312

Sampson, R. J., Morenoff, J. D., \& Earls, F. (1999). Beyond social capital: Spatial dynamics of collective efficacy for children. American Sociological Review, 64, 633-660. 
Silver, H. (2008). The process of social exclusion: The dynamics of an evolving concept. Rochester: Social Science Research Network. doi:10.2139/ssrn.1087789

Smith, H. (2008). Searching for kinship. American Behavioral Scientist, 51(6), 756-771. doi:10.1177/0002764207311986

Statistics Canada. (2013). Persons in low income before tax (in percent, 2007 to 2011). Retrieved from Statistics Canada website: http://www.statcan.gc.ca/tables-tableaux/sumsom/101/cst01/famil41a-eng.htm?sdi=low\%20income

Stein, J. A., Milburn, N. G., Zane, J. I., \& Rotheram-Borus, M. J. (2009). Paternal and maternal influences on problem behaviors among homeless and runaway youth. American Journal of Orthopsychiatry, 79(1), 39-50. doi:10.1037/a0015411

Torchalla, I., Strehlau, V., Li, K., \& Krausz, M. (2011). Substance use and predictors of substance dependence in homeless women. Drug and Alcohol Dependence, 118(2-3), 173-179. doi:10.1016/j.drugalcdep.2011.03.016

Wang, C. C. (1999). Photovoice: A participatory action research strategy applied to women's health. Journal of Women's Health, 8(2), 185-192.

Wang, C. C., Cash, J. L., \& Powers, L. S. (2000). Who knows the streets as well as the homeless? Promoting personal and community action through photovoice. Health Promotion Practice, 1, 81-89.

Webster, L. \& Perkins, D. D. (2007). Redressing structural violence against children: Empowerment-based interventions and research. In D. J. Christie, R. V. Wagner and D. A. Winter's (Eds), Peace, conflict and violence: Peace psychology for the 21 st century. Englewood Cliffs, New Jersey: Prentice-Hall.

Whitbeck, L., Hoyt, D., Yoder, K., Cauce, A., \& Paradise, M. (2001). Deviant behavior and victimization among homeless and runaway adolescents. Journal of Interpersonal Violence, 16(11), 1175-1204. doi:10.1177/088626001016011005

Zielinski, D. S. (2009). Child maltreatment and adult socioeconomic well-being. Child Abuse \& Neglect, 33(10), 666-678. doi:10.1016/j.chiabu.2009.09.001 